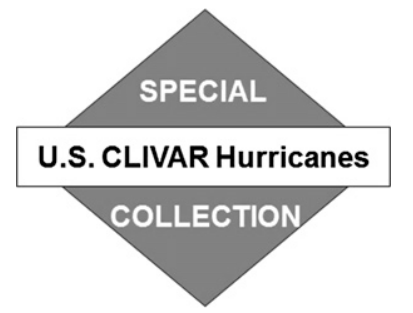

\title{
Projection of North Pacific Tropical Upper-Tropospheric Trough in CMIP5 Models: Implications for Changes in Tropical Cyclone Formation Locations
}

\author{
CHAO WANG \\ Key Laboratory of Meteorological Disaster of Ministry of Education, Joint International Research Laboratory of Climate \\ and Environment Change, Collaborative Innovation Center on Forecast and Evaluation of Meteorological Disasters, and \\ Pacific Typhoon Research Center, Nanjing University of Information Science and Technology, Nanjing, China

\section{LIGUANG WU}

\begin{abstract}
Key Laboratory of Meteorological Disaster of Ministry of Education, Joint International Research Laboratory of Climate and Environment Change, Collaborative Innovation Center on Forecast and Evaluation of Meteorological Disasters, and Pacific Typhoon Research Center, Nanjing University of Information Science and Technology, Nanjing, and State Key Laboratory of Severe Weather, Chinese Academy of Meteorological Sciences, Beijing, China
\end{abstract}

(Manuscript received 4 May 2017, in final form 13 September 2017)

\begin{abstract}
The strong westerly shear to the south flank of the tropical upper-tropospheric trough (TUTT) limits the eastward extension of tropical cyclone (TC) formation over the western North Pacific (WNP) and thus the zonal shift of the TUTT in warming scenarios has an important implication for the mean formation location of TCs. The impact of global warming on the zonal shift of the TUTT is investigated by using output from phase 5 of the Coupled Model Intercomparison Project (CMIP5) of 36 climate models in this study. It is found that considerable spread exists in the zonal position, orientation, and intensity of the simulated-climatologic TUTT in the historical runs, which is forced by observed conditions such as changes in atmospheric composition, solar forcing, and aerosols. The large spread is closely related to the diversity in the simulated SST biases over the North Pacific. Based on the 15 models with relatively high skill in their historical runs, the nearterm (2016-35) projection shows no significant change of the TUTT longitude, while the TUTT experiences an eastward shift of $1.9^{\circ}$ and $3.2^{\circ}$ longitude in the representative concentration pathway (RCP) 4.5 and 8.5 scenarios in the long-term (2081-2100) projection with considerable intermodel variability. Further examination indicates that the projected changes in the zonal location of the TUTT are also associated with the projected relative SST anomalies over the North Pacific. A stronger (weaker) relative SST warming over the North Pacific favors an eastward (westward) shift of the TUTT, suggesting that the spatial pattern of the future SST change is an important factor for the zonal shift of the mean formation location of TCs.
\end{abstract}

\section{Introduction}

Tropical cyclones (TCs) can cause enormous damages to islands and coastal areas (e.g., Pielke and Landsea 1998; Pielke et al. 2008; Zhang et al. 2009) and it is pragmatically important to know how TC activity will change in a warming climate (Knutson et al. 2010; Walsh et al. 2016). Considerable efforts have been made to understand the future change of TC behaviors (Henderson-Sellers et al. 1998; Walsh 2004; Knutson

Corresponding author: Dr. Liguang Wu, liguang@nuist.edu.cn et al. 2010; Walsh et al. 2016). So far, the projected TC activity is mainly obtained through directly calculating TC statistics from climate models in different warming scenarios (e.g., Manabe et al. 1970; Bengtsson et al.1996; Sugi et al. 2002; Chauvin et al. 2006; Zhao et al. 2009; Murakami et al. 2011, 2013; Camargo 2013) or through dynamic-statistical downscaling of specific TC features (e.g., Emanuel 1987, 2013; Knutson et al. 1998; Vecchi and Soden 2007a; Villarini and Vecchi 2012; Wang and $\mathrm{Wu} 2012$, 2015). These studies suggested that the annual frequency of TC formation will either decrease or remain essentially unchanged, with an increase in intensity 
and the associated precipitation owing to global warming (Knutson et al. 2010; Walsh et al. 2016). However, relatively few studies have been conducted on possible changes in the mean formation location of TCs and impact areas, especially in individual basins (e.g., $\mathrm{Wu}$ and Wang 2004; Knutson et al. 2010; Seneviratne et al. 2012; Christensen et al. 2013; Kossin et al. 2014; Walsh et al. 2016).

The western North Pacific (WNP) is the most active basin for TC activity (Gray 1968), and changes in the mean formation location of TCs can affect billions of people in Pacific islands and Asian coastal regions. However, only a few studies were conducted to evaluate the impact of global climate change on the formation location in the basin. While Stowasser et al. (2007) found an increase in TC formation over the South China Sea and suggested a westward shift of the mean formation location of TCs in a global warming scenario, Yokoi et al. (2009) and Murakami et al. (2011) suggested an eastward shift of the mean formation location of TCs. Some studies argued that global warming can lead to a shift of the formation location from the western to central Pacific (Li et al. 2010; Zhao and Held 2012; Zhao et al. 2013). Despite the different trends of the mean formation location of TCs, these previous studies indicate that the mean formation location of TCs in the WNP basin may change in responses to global warming.

Considering the low skill of the state-of-the-art climate models from phase 5 of the Coupled Model Intercomparison Project (CMIP5) in simulating TCs, it is hard to examine the possible shift in the mean formation location directly (Camargo 2013). As an alternative, $\mathrm{Wu}$ et al. (2015) found that the tropical upper-tropospheric trough (TUTT) in the North Pacific generally inhibits the eastward extension of TC formation as a result of the related unfavorable environments. The zonal migration of the TUTT can shift the TC formation location on the interannual and interdecadal time scales by modulating the TC genesis over the eastern WNP (Wu et al.2015; Wang and $\mathrm{Wu}$ 2016). These studies suggest that the shift of the TUTT in global warming scenarios is a good indicator for the future change of the mean location of TC formation. The objective of this study is to examine the zonal shift of the TUTT in global warming scenarios with the output of CMIP5 climate models and the future change in the mean formation location of TCs.

The remainder of this paper is organized as follows. Section 2 describes the data employed in this study, and an evaluation of the climate models is presented in section 3. Section 4 examines the future shift of the TUTT in the warming scenarios, and the uncertainty source of the projection is discussed in section 5, followed by a summary in section 6 .

\section{Data}

The monthly wind, SST, and precipitation data of the three experiments [historical and representative concentration pathway 4.5 and 8.5 (RCP4.5 and RCP8.5) experiments] from CMIP5 models are used in this study. The historical experiment is forced by observed conditions, including changes in atmospheric composition, solar forcing, natural or anthropogenic aerosols, and so on. The radiative forcing in the RCP4.5 (RCP8.5) experiments stabilizes at $4.5(8.5) \mathrm{W} \mathrm{m}^{-2}$ in 2100 (Taylor et al. 2012). The output of historical experiments during 1979-2005 from 43 models is used to examine the skills in simulating the climatological TUTT, and 36 of 43 models with RCP 4.5 and RCP8.5 experiments are used to investigate the future changes in the TUTT. The projections are divided into nearterm and long-term projections, which are expressed as the changes in 2016-35 and 2081-2100 relative to the reference period 1986-2005. The models used in this study are listed in Fig. 1.

The TC best-track dataset is from the Joint Typhoon Warming Center (JTWC). TCs are defined as those in the dataset with maximum wind speed no less than storm intensity $\left(17.2 \mathrm{~m} \mathrm{~s}^{-1}\right)$. The TC formation location is defined as the latitude and longitude when a TC for the first time reaches tropical storm intensity. The monthly wind data are from the European Centre for Medium-Range Weather Forecasts (ECMWF) interim reanalysis dataset (ERA-I; Dee et al. 2011). The monthly SST from the National Oceanic and Atmospheric Administration (NOAA) (ERSST.v3b; Smith et al. 2008) is used in this study. To evaluate the performance of CMIP5 models against the reanalysis, all of the model and reanalysis data are interpolated into $1^{\circ} \times 1^{\circ}$ grids. We focus on the peak season [July-October (JASO)] of the TC activity in the WNP.

\section{Evaluation of CMIP5 climate models}

Evaluation of the biases in historical runs is helpful to understand the future projection (Whetton et al. 2007). In this section, we focus on the performances of CMIP5 models in simulating the climatological TUTT during 1979-2005.

Figure 2a displays the mean 200-hPa streamlines and the TC formation positions during July-October over 1979-2005. The climatologic mean TUTT is elongated from northeast to southwest across the North Pacific Ocean, extending to the tropical North Pacific near $160^{\circ} \mathrm{E}$. The prominent westerly wind shear to the southeast of the TUTT trough line generally tends to suppress the $\mathrm{TC}$ formation east of $160^{\circ} \mathrm{E}$. As a result, 


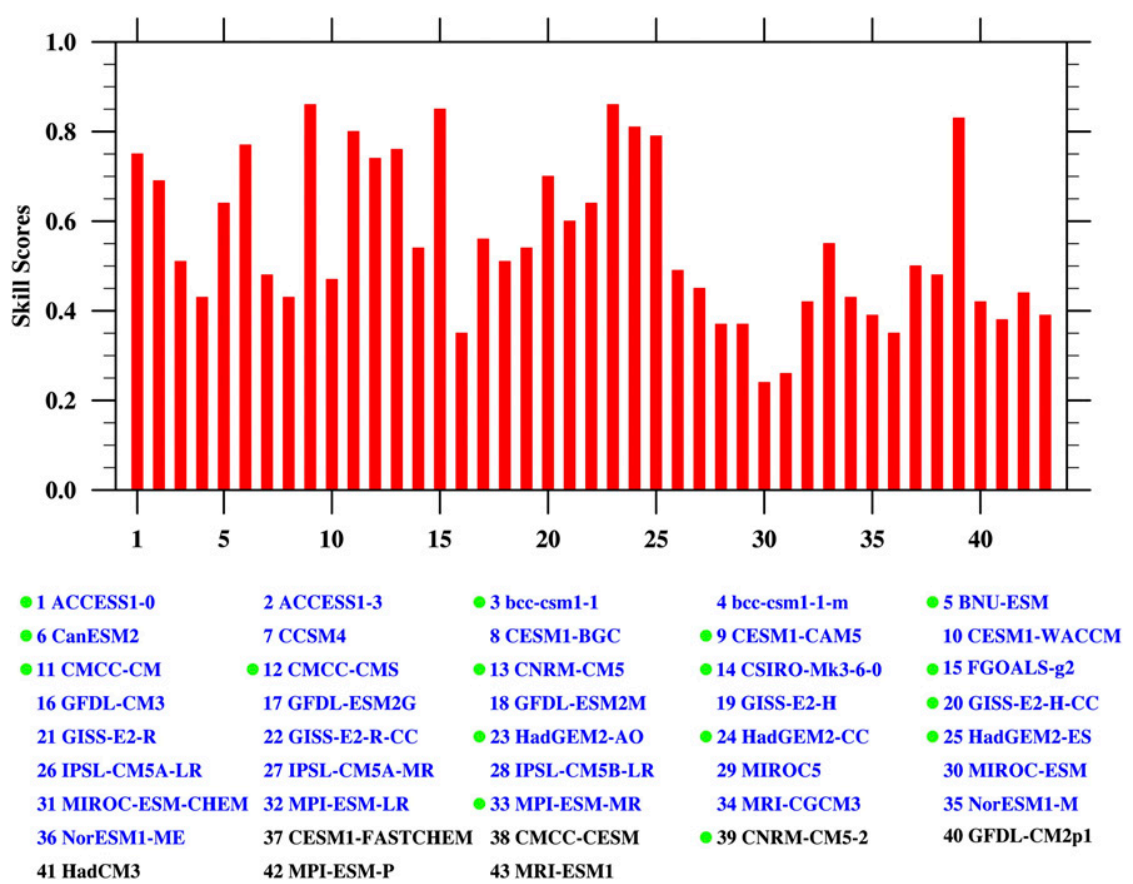

FIG. 1. Skill scores of 200 -hPa wind over $5^{\circ}-25^{\circ} \mathrm{N}, 140^{\circ} \mathrm{E}-180^{\circ}$ in historical runs of the CMIP5 models. The $x$ axis labels show the model number. The blue text presents the models available with three experiments (historical, RCP4.5, and RCP8.5), and the black text presents the models only with historical experiment. The models with green dots denote the selected models in section 3 .

Most TCs formed to west of the TUTT. As shown in Fig. 2, the north and south boundaries of the TC formation area are consistent with the subtropical westerly shear related to the midlatitude westerly jet and the tropical easterly shear associated with the South Asian high. While the vertical shear associated with the TUTT limits the eastern boundary of TC formation, it is suggested that the vertical shear is also an important factor for controlling TC activity area (e.g., Wu et al. 2015; Wang and Wu 2016).

A reasonable simulation of the climatologic TUTT is essential for using the output of a climate model to infer the change of the eastern boundary of TC formation. Figure $2 \mathrm{~b}$ shows the multimodel ensemble (MME) mean July-October streamline at $200 \mathrm{hPa}$ and vertical shear of zonal wind in the historical experiments of the 43 models during 1979-2005. It can be seen that the TUTT is reasonably well reproduced, including the northeastsouthwest orientation and strong westerly shear to its southeast. However, the cyclonic curvature of streamline near the bottom of the simulated TUTT is smaller than observation, leading to a northeastward displacement of the TUTT and a weaker simulated TUTT. Figure 2c further shows the difference of 200-hPa wind between the MME mean and ERA-I. There is an anticyclonic circulation with a center in the subtropical central Pacific (Fig. 2c). Since the TUTT is a cyclonic circulation located in this region (e.g., Sadler 1967, 1976), the anticyclonic bias makes the simulated TUTT in the CMIP5 models weaker than the observation. In fact, such an anticyclonic bias is closely associated with the southward displacement of subtropical westerly jet over the North Pacific, which is a common feature in the simulation of the CMIP5 models (e.g., Ma et al. 2015). The above evaluation shows that the northeastward displacement and weaker intensity of the TUTT are the major biases in the MME mean wind field.

Here we use a skill score defined by Taylor (2001) to quantify the model performance in the TUTT simulation. The skill score $S$ is defined as

$$
S \equiv \frac{(1+R)^{4}}{4\left(\mathrm{SDR}+\frac{1}{\mathrm{SDR}}\right)^{2}},
$$

where $R$ is the pattern correlation between a model and the ERA-I, and SDR is the ratio of spatial standard deviations of a model to that of ERA-I. The score $S$ measures the similarity of a spatial pattern to the observation. Figure 1 shows the skill scores of 200-hPa winds over $5^{\circ}-25^{\circ} \mathrm{N}, 140^{\circ} \mathrm{E}-180^{\circ}$ in 43 models. Because the TUTT bottom in observation is usually located over $5^{\circ}-25^{\circ} \mathrm{N}, 140^{\circ} \mathrm{E}-180^{\circ}$, we use the zonal wind over this 

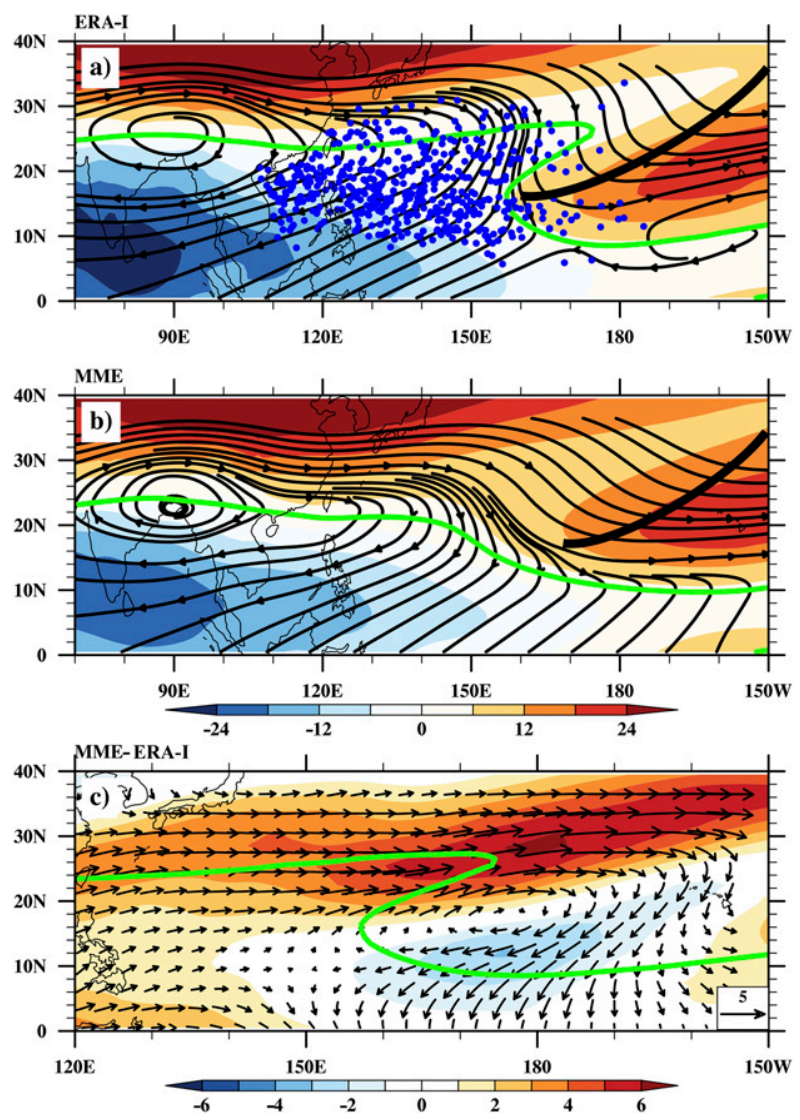

FIG. 2. (a) The 200-hPa winds (streamlines) and vertical shear of zonal wind (shading; $\mathrm{m} \mathrm{s}^{-1}$ ) averaged over 1979-2005 in ERA-I. (b) As in (a), but for the MME mean of historical runs over 19792005. (c) Difference of 200-hPa wind (vectors; $\mathrm{m} \mathrm{s}^{-1}$ ) and vertical shear of zonal wind (shading; $\mathrm{m} \mathrm{s}^{-1}$ ) between (a) and (b). The blue dots in (a) indicate TC formation locations and the thick black lines in (a) and (b) schematically indicate the trough lines of the TUTT. Green lines show the zero contours of zonal wind speed in ERA-I in (a) and (c) and MME in (b).

region to evaluate the simulated TUTT climatology in CMIP5 models. The mean skill score is 0.55 . In addition, there is considerable intermodel variations in the skill scores. In particular, the skill scores range from 0.22 in the MIROC-ESM model to 0.86 in the CESM1(CAM5) model with a standard deviation of 0.18 (hereinafter, please see http://www.ametsoc.org/PubsAcronymList for model acronym expansions). It is found that the large intermodel spread of skill scores results mainly from the different zonal locations of the simulated TUTT in the climate models. To confirm this, we further examine the longitudinal positions of the simulated TUTT. The TUTT longitude is determined by the dividing boundary (the zero contour of zonal wind speed over $5^{\circ}-20^{\circ} \mathrm{N}$ ) between the easterly and westerly wind in the trough ( $\mathrm{Wu}$ et al. 2015). Figure 3 shows the

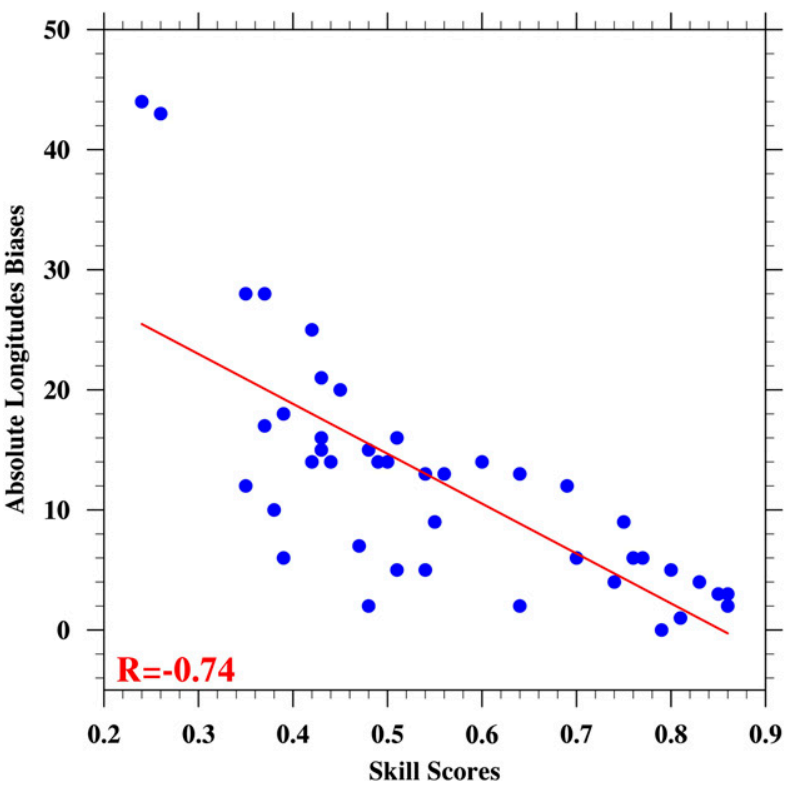

FIG. 3. Scatterplots of skill scores and the absolute TUTT longitude biases in CMIP5 models. The red line denotes linear fitting by the least squares method, and the correlation $R$ is shown in red at the bottom left.

relationship between the TUTT skill score and the absolute bias in the TUTT longitude. A significant correlation of -0.74 is found between these two measures of the simulated TUTT. That is, the model with higher skill score also shows a smaller longitude bias. This allows us to use this skill for evaluating the simulated TUTT in the climate models.

Such a large intermodel spread of skill scores and the corresponding zonal locations of the TUTT may lead to remarkable differences in their large-scale circulations and distinct eastern boundaries of the TC formation in the individual models. As a proxy, the genesis potential index (GPI) defined by Emanuel and Nolan (2004) has been widely used to demonstrate effects of large-scale environmental conditions on TC formation in climate models (e.g., Camargo et al. 2007, Yokoi et al. 2009; Murakami et al. 2011; Emanuel 2013). Figure 4 shows the GPI in the historical runs of the MIROC-ESM, GFDL CM3, and CESM1(CAM5) models during 19792005, and the corresponding spatial distribution of TC formation in the JTWC dataset. As presented in Fig. 1, the MIROC-ESM and GFDL CM3 models have a poor skill, while the TUTT is reasonably well reproduced in the CESM1(CAM5) model. The simulated TUTT experiences a westward bias in the MIROC-ESM model but an eastward displacement in the GFDL CM3 model (figure not shown). Because of the opposite bias in the zonal location of the TUTT, the corresponding spatial distribution of GPI shows a striking contrast (Figs. 4a,b) 


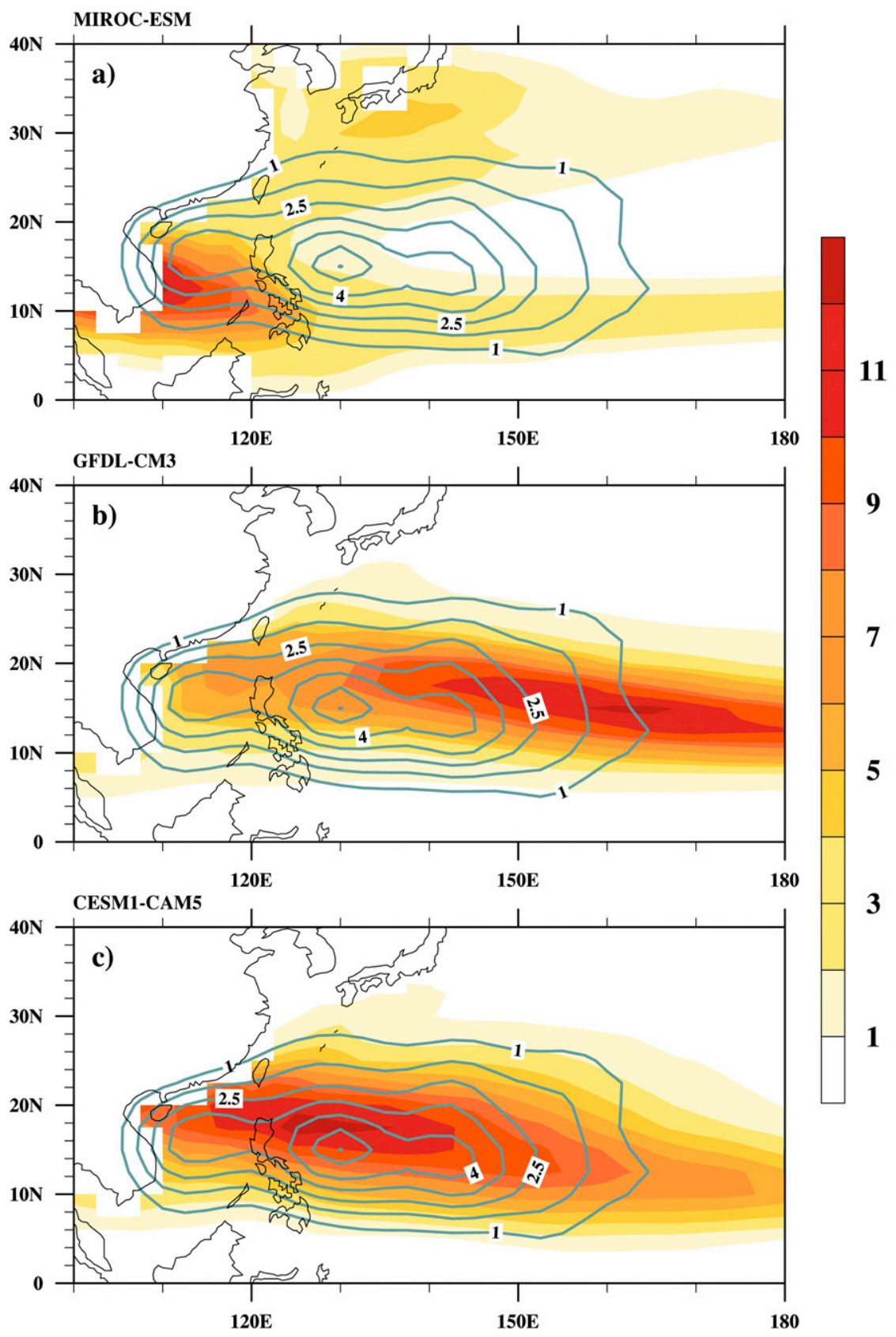

FIG. 4. The GPI (shading) in the historical runs of (a) MIROC-ESM, (b) GFDL CM3, and (c) CESM1(CAM5) models over 1979-2005. Contours show the annual frequency of the observed TC formation in the JTWC best-track dataset.

in the two models. The maximum zone of GPI is confined to the South China Sea and the TUTT shows a farther westward displacement in the MIROC-ESM model (Fig. 4a). On the other hand, the maximum center of GPI in the GFDL CM3 model is located to the east of $140^{\circ} \mathrm{E}$ owing to the eastward bias of the simulated TUTT. It is clear that a reasonable simulation of the TUTT is crucial to a good estimation of the mean area of
TC formation. As shown in Fig. 4c, the GPI in the CESM1(CAM5) model reasonably well indicates the observed spatial distribution of TC formation, with a maximum zone between $10^{\circ}-30^{\circ} \mathrm{N}$ and a maximum center from the South China Sea to east of Philippines.

There is a considerable intermodel spread in the zonal location of the simulated TUTT (Fig. 3). For instance, the TUTT longitude in MIROC-ESM model is about 
$110^{\circ} \mathrm{E}$, while it shifts to $150^{\circ} \mathrm{W}$ in the GFDL CM3 model. Since the zonal location of the TUTT is sensitive to variations in SST in the central-eastern Pacific on interannual time scale (e.g., Wang and Chan 2002; Wang and Wu 2016), we first examine the possible difference of SST anomalies in the climate models. It is found that the biases in zonal location of the TUTT are related to the SST biases over the region underlying the TUTT. Figure 5, top, shows the scatterplot of the TUTT longitude biases and SST biases over the central North Pacific $\left(10^{\circ}-30^{\circ} \mathrm{N}, 150^{\circ} \mathrm{E}-\right.$ $\left.150^{\circ} \mathrm{W}\right)$. It can be seen that the TUTT longitude biases are closely related to the SST biases in this region, with a correlation of 0.76. Fitzpatrick et al. (1995) suggested that the TUTT is maintained by the radiational cooling and subsidence feedback. The significant correlation between the SST and TUTT longitudes bias indicates the crucial role of vertical motions in the zonal TUTT location. The positive (negative) SST biases stimulate the anomalous ascending (descending) motion, leading to an eastward (westward) bias of the TUTT (Fig. 5, top).

The distinct features of large-scale environments in the climate models with various skills and zonal location of the TUTT confirm the importance of the validation. It is found that some of the models failed to simulate the climatological TUTT in their historical runs. Therefore, we should exclude the models with poor performance and select models with relatively higher skill in simulating the TUTT for further projection. Among the 43 total simulations, 16 models exhibit relatively higher skill in simulating the climatological TUTT, with skill scores exceeding 0.5 and longitude biases of the TUTT less than $10^{\circ}$. Because the RCP4.5 and RCP8.5 projections are not available in the CNRM-CM5.2 model, only 15 models are selected for further analysis (Fig. 1).

\section{Zonal shift of the TUTT in the warming scenarios}

This section focuses on the zonal location of the TUTT in the RCP4.5 and RCP8.5 scenarios. Following the Fifth Assessment Report (AR5) of the United Nations Intergovernmental Panel on Climate Change (IPCC), the projections are divided into near-term and long-term projections, which are expressed as the changes in 2016-35 and 2081-2100 relative to the reference period 1986-2005, respectively.

\section{a. Near-term projection}

Figure 6a shows selected 15-model MME mean change in $200-\mathrm{hPa}$ wind over $2016-35$ in the RCP4.5 scenario. It is featured with anomalous westerlies in zonal band of $10^{\circ}-25^{\circ} \mathrm{N}$ and easterlies anomalies north of $30^{\circ} \mathrm{N}$, constructing an anomalous cyclonic circulation over the
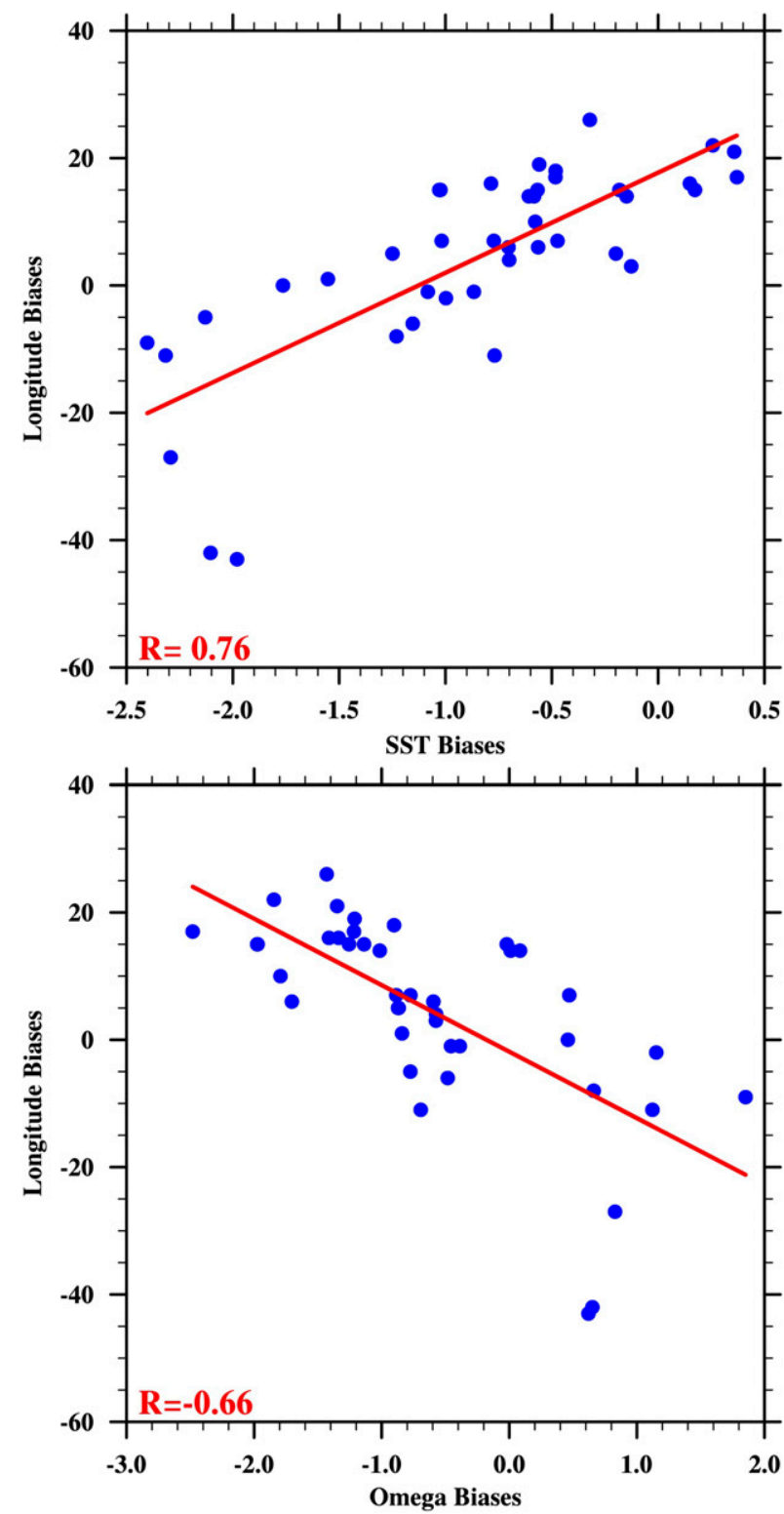

FIG. 5. Scatterplot of (top) the TUTT longitude biases and SST biases and (bottom) the TUTT longitude biases $\left({ }^{\circ}\right.$ lon) and vertical motion biases $\left(10^{-2} \mathrm{~Pa} \mathrm{~s}^{-1}\right)$ over $10^{\circ}-30^{\circ} \mathrm{N}, 150^{\circ} \mathrm{E}-150^{\circ} \mathrm{W}$ in CMIP5 models. The red lines denote linear fitting by the least squares method and the correlation $R$ is shown in red at the bottom left in each panel.

subtropical North Pacific. Accordingly, the zonal wind shear increases between $10^{\circ}$ and $25^{\circ} \mathrm{N}$. The westerly anomalies between $10^{\circ}$ and $25^{\circ} \mathrm{N}$ enhance the westerly near the western end of the TUTT, and the anomalous cyclonic circulation also intensifies the cyclonic curve associated with the TUTT. As shown in Fig. 6b, most of the selected models show a westwardshift with variable magnitudes, and the MME mean indicates a slight westward shift of $0.7^{\circ}$ longitude during this 

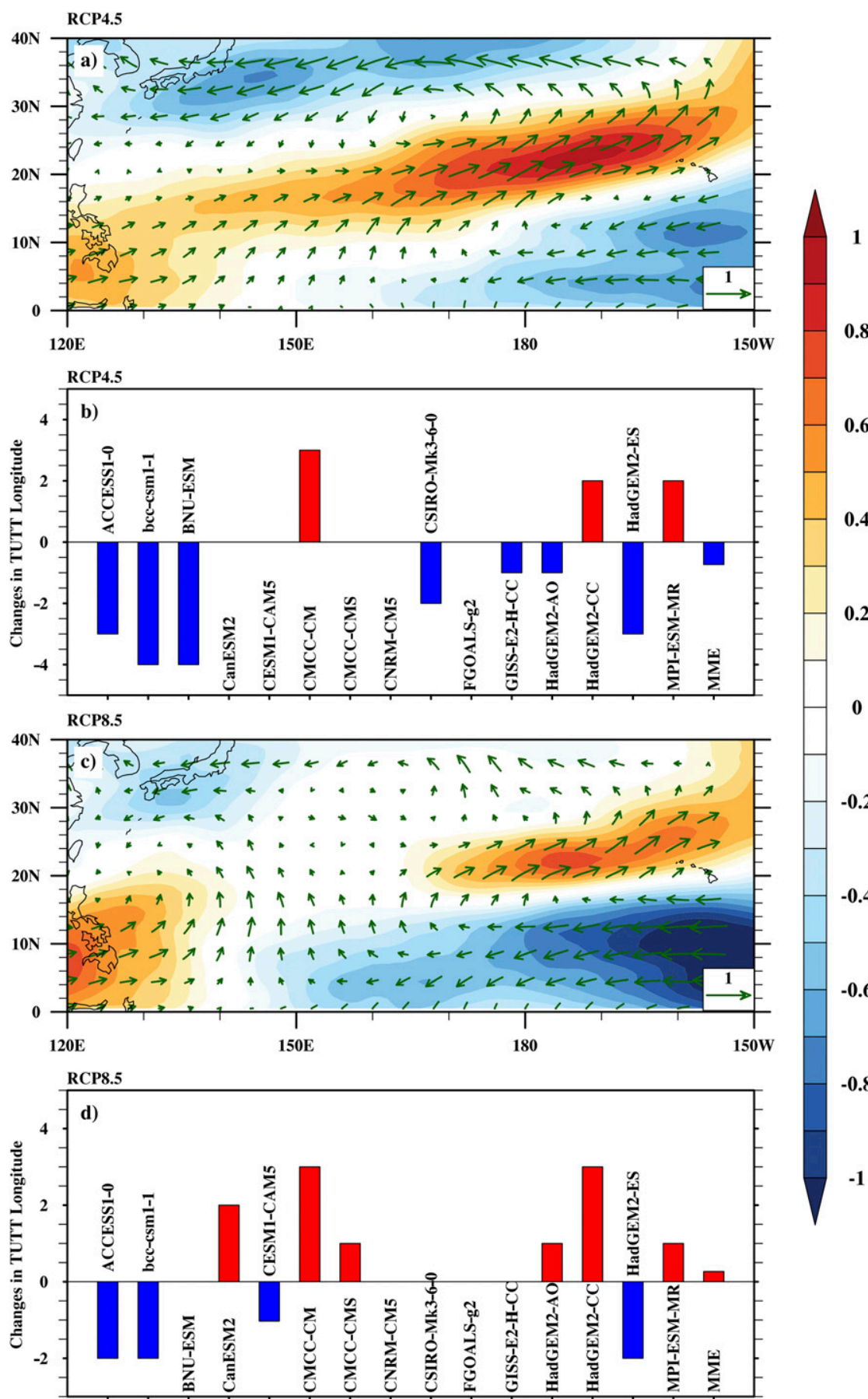

FIG. 6. (a) Changes of the 15-model MME mean 200-hPa wind (vectors; $\mathrm{m} \mathrm{s}^{-1}$ ) and the vertical shear of zonal wind (shading; $\mathrm{m} \mathrm{s}^{-1}$ ), and (b) changes of the TUTT longitude ( ${ }^{\circ}$ lon) in each model and the corresponding MME mean (the rightmost bar) between 2016-35 and 19862005 in RCP4.5 scenario. (c),(d) As in (a),(b), but for the RCP8.5 scenario.

period. As the radiative forcing increases in the RCP8.5 scenario, the westerly anomalies in the RCP4.5 scenario weakens and the easterly anomalies in the tropical eastern-central Pacific extend westward (Fig. 6c). Figure $6 \mathrm{~d}$ shows the changes of zonal location of the
TUTT in the individual models. There is a large intermodel spread in the migration of the TUTT, and the MME mean shows a slightly eastward shift of $0.3^{\circ}$ longitude. It is found that the zonal location of the TUTT experiences little shift in both scenarios during 2016-35. 
The CMIP5 models initialized by randomly selected preindustrial states, so the inherent variability in projections is not synchronized with observations, and thus the MME mean is only an estimate of responses of external forcing (e.g., Meehl et al. 2014; Dai et al. 2015). Note that the internal variability plays a dominant role since the effects of external forcing are still small in the near-term projection (e.g., Hawkins and Sutton 2009; Meehl et al. 2009, 2014). The results suggested that the zonal shift in the TUTT may generally determine by the internal variability of the climate system in the nearterm projection.

\section{b. Long-term projection}

Previous studies found that the climate response becomes prominent and the contribution from internal variability falls very rapidly with the increase of the projection time as the signal of climate change strengthens, while the amplitude of internal variability remains constant (Cox and Stephenson 2007; Hawkins and Sutton 2009). Changes in the late-twenty-first century can be viewed as the responses to external forcing of the climate system. Figure 7a shows the changes of the selected 15-model MME 200-hPa wind over 2081-2100 in RCP4.5 scenario. As the forcing increases with time, the changes generally have a greater magnitude than that of 2016-35. The most prominent feature is the easterly anomalies and the associated anomalous easterly shear to the south of $25^{\circ} \mathrm{N}$. Such wind anomalies will weaken the westerly associated with the TUTT, decreasing the westerly shear and shifting the TUTT eastward. The corresponding changes in the RCP8.5 scenario also show a similar result but with a greater magnitude under the stronger radiative forcing (Fig. 7c). For instance, changes in vertical zonal shear over $5^{\circ}-$ $20^{\circ} \mathrm{N}, 150^{\circ} \mathrm{E}-180^{\circ}$ is $-2.1 \mathrm{~m} \mathrm{~s}^{-1}$ in the RCP8.5 scenario, while that in RCP4.5 scenario is only $-0.9 \mathrm{~m} \mathrm{~s}^{-1}$. Previous studies have shown that vertical shear in this region exerts great impacts on TC formation over the WNP (e.g., Chan 2008; Liu and Chan 2013; Wu et al. 2015); such a weakening in the vertical shear indicates an eastward shift of TC formation during the late twentyfirst century. In addition, there is an anomalous cyclonic circulation east of $140^{\circ} \mathrm{E}$. Wang and Wu (2015) suggested that this anomalous cyclonic circulation would steer more TCs landing over eastern China. Figures 7b-d further demonstrate changes in the TUTT longitudes in individual selected models. In accordance with the anomalous easterly over the eastern WNP, two-thirds of the selected models show an eastward shift of the TUTT in both scenarios. The MME mean changes of the TUTT longitude are $1.9^{\circ}$ and $3.2^{\circ}$ in the RCP4.5 and RCP8.5 scenarios, respectively, suggesting an eastward migration of the TUTT over 2081-2100. It should be noted that the projected eastward projection is different from that of $\mathrm{Wu}$ et al. (2015), which suggested a westward shift of the TUTT during 1979-2012. Some studies found that the Pacific SST experienced a La Niña-like change during this period (e.g., Burgman et al. 2008; Wang et al. 2013), and such a change increased the eastwest SST gradient over the North Pacific. It favors the westward shift of the TUTT as well as the TC formation location (Wu et al. 2015). However, the SST warming anomaly in the long-term projection shows a greater amplitude over the eastern North Pacific than that of the western North Pacific (see Fig. 9a), decreasing the eastwest SST gradient, and thus favoring the eastward shift of the TUTT. These results, in fact, indicate the potential important role of anomalous SST patterns on the TUTT migration.

\section{Influence of SST over the North Pacific on the zonal shift of the TUTT in the warming scenarios}

To understand the intermodel spread in the projection of the TUTT shift, we examine all of the 36 models available with three experiments (historical, RCP4.5, and RCP8.5 experiments) in this section. Given poor skills in simulating the climatological TUTT in some models (Fig. 3), we define an index for the zonal shift of the TUTT in the warming scenarios, which is the negative change of the $200-\mathrm{hPa}$ zonal wind averaged over $5^{\circ}-$ $20^{\circ} \mathrm{N}, 150^{\circ} \mathrm{E}-180^{\circ}$. The zonal wind in this region is a good indicator of the TUTT longitudes in historical runs and global warming experiments in the selected climate models, with a correlation exceeding 0.9 in the three types of the experiments (figure not shown). The reason for using the negative changes in zonal wind is to make the index the same sign with the TUTT shift direction (i.e., the positive index anomaly corresponds to the eastward shift of the TUTT).

Figure 8 shows the TUTT index of the 36 models over 2081-2100 in the RCP8.5 scenario. The MME mean shows an increase of easterly wind in this region, indicating an eastward shift of the TUTT (Fig. 7). Such an MME mean eastward shift results mainly from the greater magnitude of eastward migration than that of westward migration. As shown in Fig. 8, there is a considerable intermodel spread in the projected zonal shift of the TUTT. Of the 36 models, 19 project an eastward shift, while the TUTTs in the other 17 models show a westward shift. Of the 15 selected models, 11 are from the group with the eastward shift, resulting in the projected eastward migration of the TUTT (Fig. 7).

What determine the projected zonal shift of the TUTT in the MME mean and individual models? The 

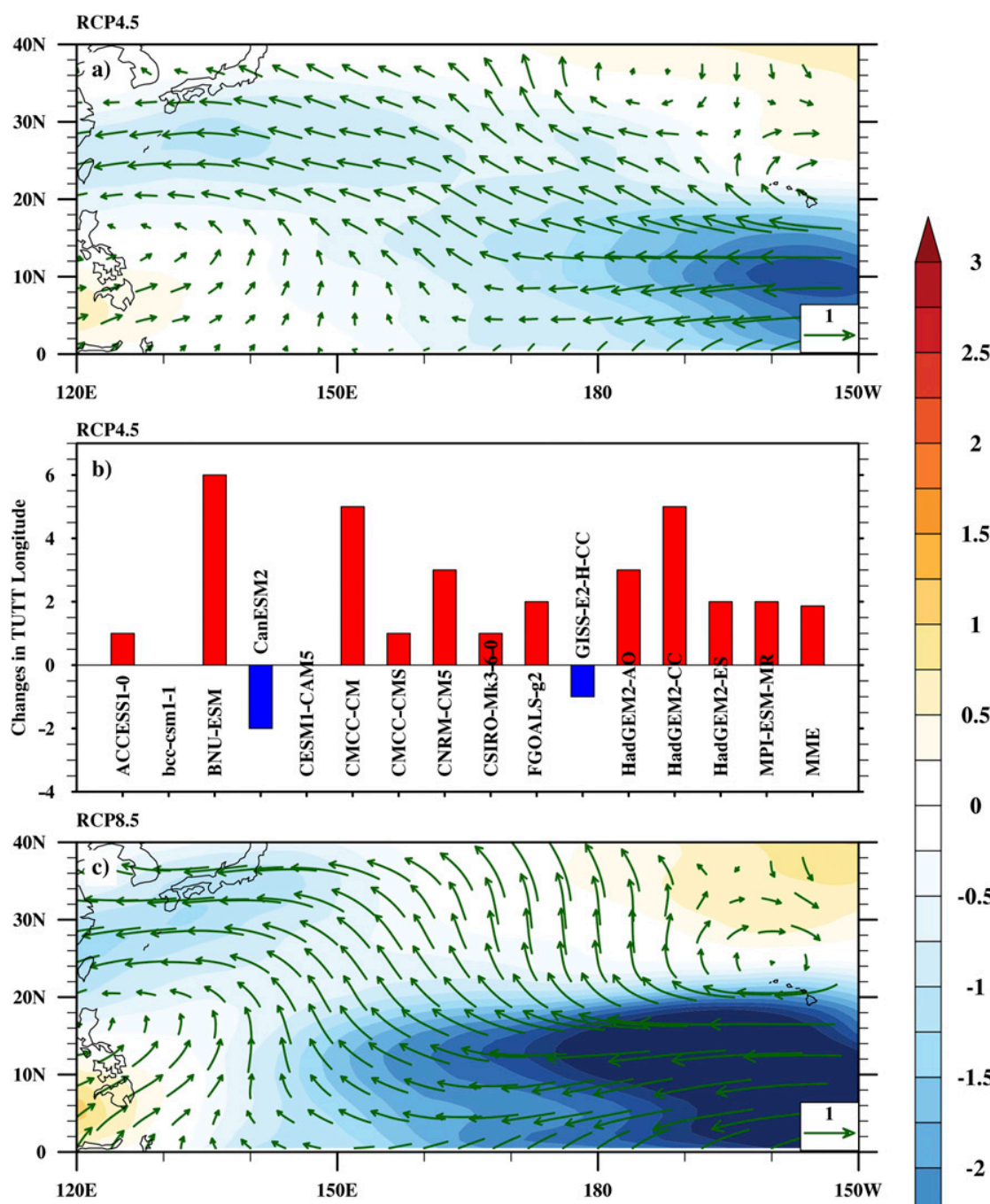


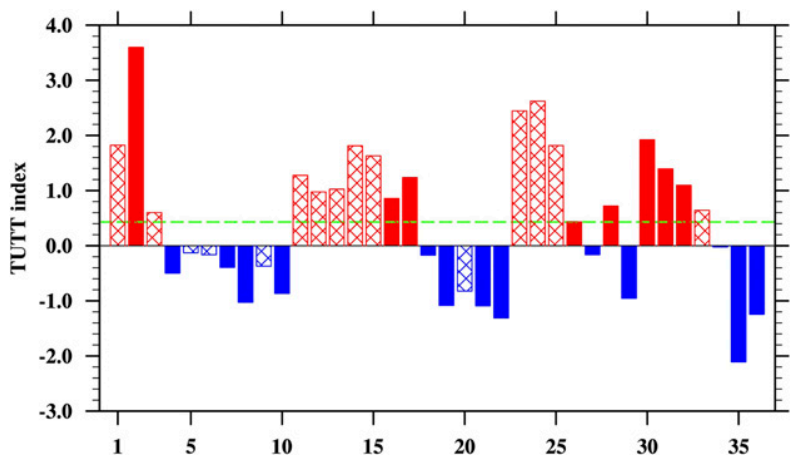

FIG. 8. TUTT index of 36 models over 2081-2100 in RCP8.5 scenario relative to 1986-2005. The $x$ axis labels show the model number from Fig. 1. The red (blue) bars denote the changes greater (less) than zero. Hatched bars denote the 15 selected models and the green dashed line denotes the mean change.

suppressing the sea surface evaporation and further leading to the SST warming in this region. In fact, the westerly wind anomalies in the tropical WNP indicate the eastward extension of the monsoon trough, which is in accordance with the eastward shift of the TUTT in the MME mean (Fig. 8).

To further understand the spread source in the projected zonal shift of the TUTT, we regressed the normalized TUTT index onto the relative SST and 200-hPa wind changes in the 36 models over 2081-2100 in the RCP8.5 scenario. Previous studies suggested that the relative SST warming pattern, not the magnitude of SST warming, can influence large-scale circulations in warming scenarios (e.g., Vecchi and Soden 2007b, hereafter VS07; Johnson and Xie 2010). Following VS07, the relative SST is defined as the anomalous SST relative to the global tropics $20^{\circ} \mathrm{S}-20^{\circ} \mathrm{N}$. Our purpose of using the relative SST is to remove the different warming magnitudes in various projection periods and scenarios, and emphasize the influences of the relative SST warming on large-scale circulations. In fact, the relative SST can indicate the impacts of SST change on large scale circulations in different climate scenarios because it including the effects of SST gradient (e.g., Lindzen and Nigam 1987) as well as changing SST threshold for convection (e.g., Johnson and Xie 2010), while the local absolute SST can only work in a single climate scenario. Therefore, when we consider different scenarios and periods, the relative SST is more reasonable than the absolute local SST because of the different warming magnitudes in various projection periods and scenarios. As shown in Fig. 9b, the anomalous SST pattern associated with eastward shift of the TUTT is characterized by stronger SST warming over the central and eastern North Pacific, and relatively weaker warming over the WNP. At the upper levels, there is an anomalous
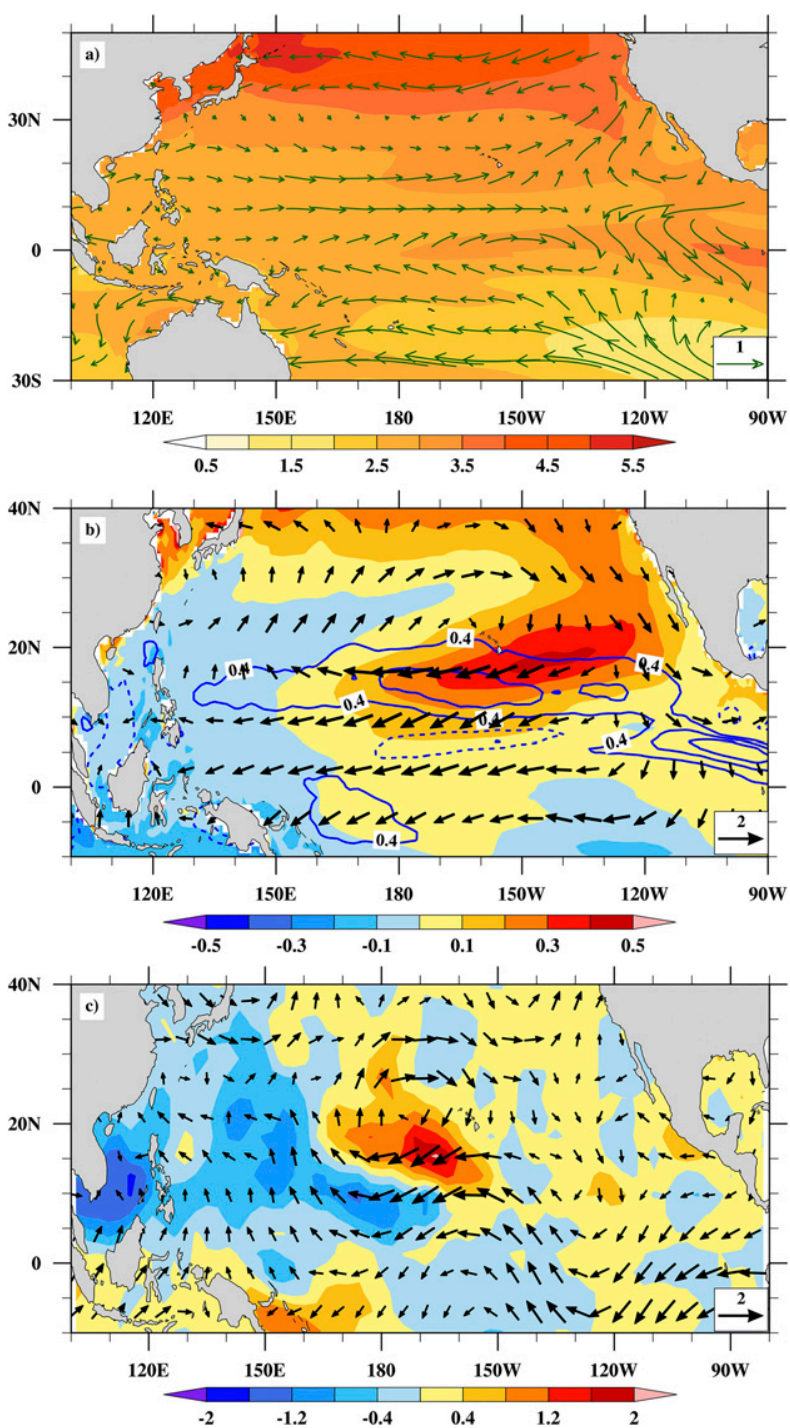

FIG. 9. (a) Changes of the 36-model MME mean SST (shading; $\mathrm{K}$ ) and $850-\mathrm{hPa}$ wind (vectors; $\mathrm{m} \mathrm{s}^{-1}$ ) over 2081-2100 in RCP8.5 scenario. (b) Intermodel regression of relative SST anomalies (shading; K), precipitation (contours; $\mathrm{mm} \mathrm{day}^{-1}$ ), and $200-\mathrm{hPa}$ wind anomalies (vectors; $\mathrm{m} \mathrm{s}^{-1}$ ) with respect to the normalized TUTT index over 2081-2100 in RCP8.5 scenario relative to 19862005. (c) Simulated difference in precipitation (shading; $\mathrm{mm} \mathrm{day}^{-1}$ ) and $200-\mathrm{hPa}$ wind (vectors; $\mathrm{m} \mathrm{s}^{-1}$ ) between the sensitivity and control experiments.

anticyclonic circulation located at the central and eastern North Pacific, which is consistent with the projected eastward shift of the TUTT. We also examined the capacity of the CMIP5 models in reproducing the observed TUTT-SST relationship. It is found that the anomalous SST pattern associated with the eastward shift of the TUTT in observation is reasonably reproduced by the CMIP5 models, which resembles that in Fig. $9 b$.

To investigate the associated mechanism of the TUTT migration, we designed idealized numerical experiments 
by using the ECHAM version 5.3 atmospheric global climate model (hereafter ECHAM5), which was developed by the Max Planck Institute for Meteorology (MPI; Roeckner et al. 2003). The model was run at a horizontal resolution of spectral triangular 42 (T42), with 31 vertical levels in a hybrid sigma-pressure coordinate system. The control run is forced by the Hadley Centre Sea Ice and Sea Surface Temperature data, which are averaged from 1970 to 1999 . The sensitivity run is identical to control run except that the regressed SST anomaly over the North Pacific $\left(10^{\circ}-30^{\circ} \mathrm{N}, 150^{\circ} \mathrm{E}-\right.$ $150^{\circ} \mathrm{W}$ ) in Fig. 9b was added to the climatological SST. For each experiment, a 32-yr integration was conducted and the last 30 years of results are used to construct the 30 ensemble members. The ensemble mean of JulyOctober is analyzed. Figure $9 \mathrm{c}$ shows the simulated difference in $200-\mathrm{hPa}$ wind and precipitation between control run and sensitivity run. As shown in Fig. 9, the warm SST anomalies in the central and eastern Pacific enhance the precipitation in this region, and the associated convective heating further stimulates westerly anomalies at low levels to its west (Matsuno 1966; Gill 1980), extending the monsoon trough eastward (Fig. 9a). In the upper troposphere, the TUTT shifts eastward as a result of the stimulated anticyclonic wind anomalies by increased convective heating in central and eastern Pacific (Figs. 9b,c). Additionally, the enhanced vertical motion over the central and eastern Pacific is unfavorable for the maintaining of radiational cooling and subsidence feedback in the TUTT (Fitzpatrick et al. 1995). To confirm this relationship, Fig. 10 further shows the scatterplot of the TUTT index and the anomalous relative SST over $10^{\circ}-30^{\circ} \mathrm{N}, 150^{\circ} \mathrm{E}-150^{\circ} \mathrm{W}$ in the nearterm and long-term projections in the RCP4.5 and RCP8.5 scenarios. The changes in zonal wind associated with the TUTT migration are closely related to the relative SST over the North Pacific, with a correlation of 0.69. That is, a stronger (weaker) relative SST warming over the North Pacific favors an eastward (westward) shift of the TUTT. The diverse future changes in the zonal location of the TUTT are related to projected relative SST anomalies in the Pacific. It is suggested that the spatial pattern of the future SST change is an important factor in the change of TC formation location.

\section{Summary}

The strong westerly shear to the south flank of the TUTT limits the east boundary of tropical cyclone (TC) formation over the WNP and thus the zonal shift of the TUTT in warming scenarios has an important implication for the mean formation location of TCs. Using the output of the CMIP5 models, it is found that

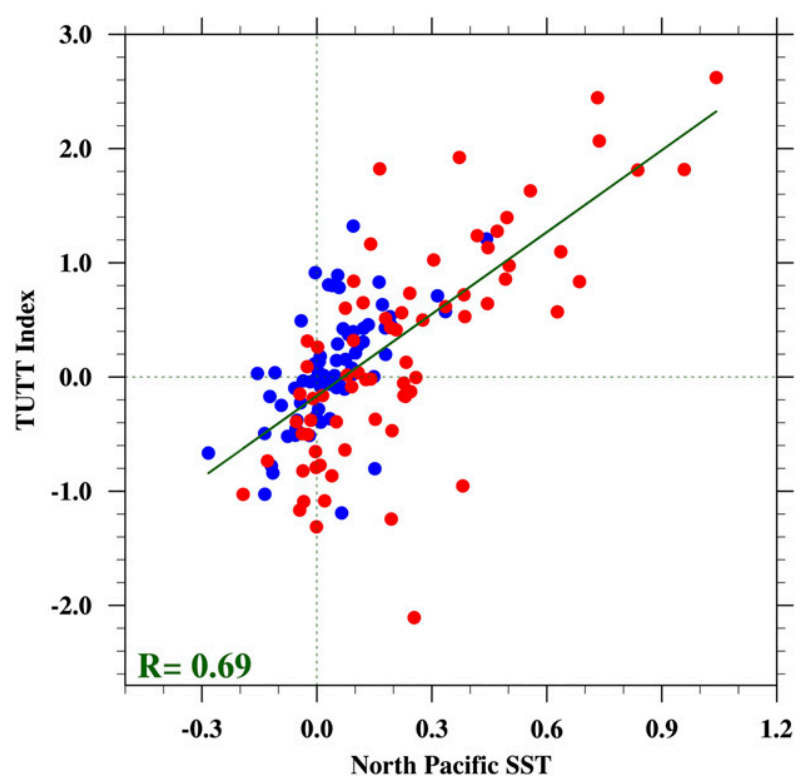

FIG. 10. Scatterplot of the TUTT index and the relative SST anomaly $(\mathrm{K})$ over the North Pacific $\left(10^{\circ}-30^{\circ} \mathrm{N}, 150^{\circ} \mathrm{E}-150^{\circ} \mathrm{W}\right)$ in near-term (blue dots) and long-term (red dots) projections in RCP4.5 and RCP8.5 scenarios. The green line denotes linear fitting by the least squares method and the correlation $R$ is shown in green at the bottom left.

considerable spreads exist in the zonal position, orientation, and intensity of the simulated-climatologic TUTTs in the historical runs. The large spread results mainly from the diversity in the simulated SST patterns over the North Pacific. Since some of the models failed to simulate the climatological TUTT, 15 of them with relatively higher skill in their historical runs are used for the future projection. Based on the 15 selected models, it is found that the zonal location of the TUTT experiences little shift in both the RCP4.5 and RCP8.5 scenarios during 2016-35. As the external forcing increases over time, the TUTT shifts eastward by $1.9^{\circ}$ and $3.2^{\circ}$ longitude in RCP4.5 and RCP 8.5 scenarios during 2081-2100, respectively. Such an eastward migration of the TUTT and the associated large-scale conditions may favor the TC formation over the eastern WNP, shifting the TC formation locations eastward. The eastward shift of the formation location makes TCs have longer time over the tropical warm ocean and get stronger intensity (e.g., Wang and Chan 2002; Camargo and Sobel 2005; Zhan et al. 2011; Zhao et al. 2011).

Although the MME mean of selected models shows an eastward shift, considerable intermodel variability is found in the projected migration of the TUTT in all available 36 models. About half of the models project an eastward shift and other half of the models project a westward shift. The projected changes in the zonal 
location of the TUTT are dominated by the future changes in relative SST anomalies over the North Pacific. A stronger (weaker) relative SST warming over the North Pacific favors an eastward (westward) shift of the TUTT. It is suggested that the spatial pattern of future SST change is an important factor for the change of the mean formation of TCs.

Acknowledgments. This research was jointly supported by the National Basic Research Program of China (2013CB430103 and 2015CB452803), the National Natural Science Foundation of China (Grants 41730961, 41675051, 41705060, 41375056, and 41675072), the Natural Science Foundation for Higher Education Institutions in Jiangsu Province (12KJA170002), the Natural Science Foundation of Jiangsu Province (BK20170941), the project of the specially appointed professorship of Jiangsu Province, the Startup Foundation for Introducing Talent of NUIST (Grant 2016r048), and the Priority Academic Program Development of Jiangsu Higher Education Institutions (PAPD). The authors thank Dr. Jian Cao for helpful discussions about numerical experiments.

\section{REFERENCES}

Bengtsson, L., M. Botzet, and M. Esch, 1996: Will greenhouse gas-induced warming over the next 50 years lead to higher frequency and greater intensity of hurricanes? Tellus, $\mathbf{4 8 A}$, 57-73, https://doi.org/10.3402/tellusa.v48i1.11632.

Burgman, R. J., A. C. Clement, C. M. Mitas, J. Chen, and K. Esslinger, 2008: Evidence for atmospheric variability over the Pacific on decadal timescales. Geophys. Res. Lett., 35, L01704, https://doi.org/10.1029/2007GL031830.

Camargo, S. J., 2013: Global and regional aspects of tropical cyclone activity in the CMIP5 models. J. Climate, 26, 9880-9902, https://doi.org/10.1175/JCLI-D-12-00549.1.

— intensity and ENSO. J. Climate, 18, 2996-3006, https://doi.org/ 10.1175/JCLI3457.1.

,-- , A. G. Barnston, and K. A. Emanuel, 2007: Tropical cyclone genesis potential index in climate models. Tellus, $\mathbf{5 9 A}$, 428-443, https://doi.org/10.1111/j.1600-0870.2007.00238.x.

Chan, J. C. L., 2008: Decadal variations of intense typhoon occurrence in the western North Pacific. Proc. Roy. Soc. London, 464A, 249-272, https://doi.org/10.1098/rspa.2007.0183.

Chauvin, F., J.-F. Royer, and M. Déqué, 2006: Response of hurricane-type vortices to global warming as simulated by ARPEGE-Climat at high resolution. Climate Dyn., 27, 377399, https://doi.org/10.1007/s00382-006-0135-7.

Christensen, J. H., and Coauthors, 2013: Climate phenomena and their relevance for future regional climate change. Climate Change 2013: The Physical Science Basis, T. F. Stocker et al., Eds., Cambridge University Press, 1217-1308.

Cox, P., and D. Stephenson, 2007: A changing climate for prediction. Science, 317, 207-208, https://doi.org/10.1126/science.1145956.

Dai, A., J. C. Fyfe, S.-P. Xie, and X. Dai, 2015: Decadal modulation of global surface temperature by internal climate variability.
Nat. Climate Change, 5, 555-559, https://doi.org/10.1038/ nclimate2605.

Dee, D., and Coauthors, 2011: The ERA-Interim reanalysis: Configuration and performance of the data assimilation system. Quart. J. Roy. Meteor. Soc., 137, 553-597, https://doi.org/ 10.1002/qj.828.

Emanuel, K. A., 1987: The dependence of hurricane intensity on climate. Nature, 326, 483-485, https://doi.org/10.1038/326483a0.

_ 2013: Downscaling CMIP5 climate models shows increased tropical cyclone activity over the 21st century. Proc. Natl. Acad. Sci. USA, 110, 12 219-12 224, https://doi.org/10.1073/ pnas.1301293110.

— , and D. S. Nolan, 2004: Tropical cyclone activity and the global climate system. Preprints, 26th Conf. on Hurricanes and Tropical Meteorology, Miami, FL, Amer. Meteor. Soc., 10A.2, https://ams.confex.com/ams/26HURR/techprogram/ paper_75463.htm.

Fitzpatrick, P. J., J. A. Knaff, C. W. Landsea, and S. V. Finley, 1995: A systematic bias in the aviation model's forecast of the Atlantic tropical upper tropospheric-trough: Implications for tropical cyclone forecasting. Wea. Forecasting, 10, 433-446, https://doi.org/10.1175/1520-0434(1995)010<0433: DOASBI $>2.0 . \mathrm{CO} ; 2$.

Gill, A. E., 1980: Some simple solutions for heat-induced tropical circulation. Quart. J. Roy. Meteor. Soc., 106, 447-462, https:// doi.org/10.1002/qj.49710644905.

Gray, W. M., 1968: Global view of the origin of tropical disturbances and storms. Mon. Wea. Rev., 96, 669-700, https://doi.org/ 10.1175/1520-0493(1968)096<0669:GVOTOO >2.0.CO;2.

Hawkins, E., and R. Sutton, 2009: The potential to narrow uncertainty in regional climate predictions. Bull. Amer. Meteor. Soc., 90, 1095-1107, https://doi.org/10.1175/2009BAMS2607.1.

Henderson-Sellers, A., and Coauthors, 1998: Tropical cyclones and global climate change: A post-IPCC assessment. Bull. Amer. Meteor. Soc., 79, 19-38, https://doi.org/10.1175/ 1520-0477(1998)079<0019:TCAGCC >2.0.CO;2.

Johnson, N. C., and S. P. Xie, 2010: Changes in the sea surface temperature threshold for tropical convection. Nat. Geosci., $\mathbf{3}$, 842-845, https://doi.org/10.1038/ngeo1008.

Knutson, T. R., R. E. Tuleya, and Y. Kurihara, 1998: Simulated increase of hurricane intensities in a $\mathrm{CO}_{2}$-warmed climate. Science, 279, 1018-1021, https://doi.org/10.1126/ science.279.5353.1018.

— , and Coauthors, 2010: Tropical cyclones and climate change. Nat. Geosci., 3, 157-163, https://doi.org/10.1038/ngeo779.

Kossin, J. P., K. A. Emanuel, and G. A. Vecchi, 2014: The poleward migration of the location of tropical cyclone maximum intensity. Nature, 509, 349-352, https://doi.org/10.1038/nature13278.

Li, T., M. Kwon, M. Zhao, J. S. Kug, J. J. Luo, and W. Yu, 2010: Global warming shifts Pacific tropical cyclone location. Geophys. Res. Lett., 37, L21804, https://doi.org/10.1029/ 2010 GL045124.

Lindzen, R. S., and S. Nigam, 1987: On the role of sea surface temperature gradients in forcing low-level winds and convergence in the tropics. J. Atmos. Sci., 44, 2418-2436, https:// doi.org/10.1175/1520-0469(1987)044<2418:OTROSS >2.0.CO;2.

Liu, K. S., and J. C. L. Chan, 2013: Inactive period of western North Pacific tropical cyclone activity in 1998-2011. J. Climate, 26, 2614-2630, https://doi.org/10.1175/JCLI-D-12-00053.1.

Ma, J., H. Xu, and P. Lin, 2015: Meridional position biases of East Asian subtropical jet stream in CMIP5 models and their relationship with ocean model resolutions. Int. J. Climatol., 35, 3942-3958, https://doi.org/10.1002/joc.4256. 
Manabe, S., J. L. Holloway Jr., and H. M. Stone, 1970: Tropical circulation in a time-integration of a global model of the atmosphere. J. Atmos. Sci., 27, 580-613, https://doi.org/10.1175/ 1520-0469(1970)027<0580:TCIATI >2.0.CO;2.

Matsuno, T., 1966: Quasi-geostrophic motions in the equatorial area. J. Meteor. Soc. Japan, 44, 25-43, https://doi.org/10.2151/ jmsj1965.44.1_25.

Meehl, G. A., and Coauthors, 2009: Decadal prediction: Can it be skillful? Bull. Amer. Meteor. Soc., 90,1467-1485, https:// doi.org/10.1175/2009BAMS2778.1.

— , H. Teng, and J. M. Arblaster, 2014: Climate model simulations of the observed early-2000s hiatus of global warming. Nat. Climate Change, 4, 898-902, https://doi.org/10.1038/ nclimate2357.

Murakami, H., B. Wang, and A. Kitoh, 2011: Future change of western North Pacific typhoons: Projections by a 20-km-mesh global atmospheric model. J. Climate, 24, 1154-1169, https:// doi.org/10.1175/2010JCLI3723.1.

_- M. Sugi, and A. Kitoh, 2013: Future changes in tropical cyclone activity in the North Indian Ocean projected by highresolution MRI-AGCMs. Climate Dyn., 40,1949-1968, https:// doi.org/10.1007/s00382-012-1407-z.

Pielke, R. A., Jr., and C. W. Landsea, 1998: Normalized hurricane damages in the United States: 1925-95. Wea. Forecasting, 13, 621-631, https://doi.org/10.1175/1520-0434(1998)013<0621: NHDITU $>2.0 . \mathrm{CO} ; 2$.

- J. Gratz, C. W. Landsea, D. Collins, M. Saunders, and R. Musulin, 2008: Normalized hurricane damages in the United States: 1900-2005. Nat. Hazards Rev., 9, 29-42, https:// doi.org/10.1061/(ASCE)1527-6988(2008)9:1(29).

Roeckner, E., and Coauthors, 2003: The atmospheric general circulation model ECHAM5. Part I: Model description. Rep. No. 349, Max-Planck-Institute für Meteorologie, Hamburg, Germany, $127 \mathrm{pp}$.

Sadler, J. C., 1967: The tropical upper tropospheric trough as a secondary source of typhoons and a primary source of trade wind disturbances. Hawaii Institute of Geophysics (HIG) Rep. 67-12, 103 pp. [Available from HIG, 2525 Correa Rd., Honolulu, HI 96822.]

_ 1976: A role of the tropical upper tropospheric trough in early season typhoon development. Mon. Wea. Rev., 104, 1266-1278, https://doi.org/10.1175/1520-0493(1976)104<1266: AROTTU $>2.0 . \mathrm{CO} ; 2$.

Seneviratne, S. I., and Coauthors, 2012: Changes in climate extremes and their impacts on the natural physical environment. Managing the Risks of Extreme Events and Disasters to Advance Climate Change Adaptation, C. B. Field et al., Eds., Cambridge University Press, 109-230.

Smith, T. M., R. W. Reynolds, T. C. Peterson, and J. Lawrimore, 2008: Improvements to NOAA's historical merged landocean surface temperature analysis (1880-2006). J. Climate, 21, 2283-2296, https://doi.org/10.1175/2007JCLI2100.1.

Stowasser, M., Y. Wang, and K. Hamilton, 2007: Tropical cyclone changes in the western North Pacific in a global warming scenario. J. Climate, 20, 2378-2396, https://doi.org/10.1175/ JCLI4126.1.

Sugi, M., A. Noda, and N. Sato, 2002: Influence of the global warming on tropical cyclone climatology: An experiment with the JMA global model. J. Meteor. Soc. Japan, 80, 249-272, https://doi.org/10.2151/jmsj.80.249.

Taylor, K. E., 2001: Summarizing multiple aspects of model performance in a single diagram. J. Geophys. Res., 106, 71837192, https://doi.org/10.1029/2000JD900719.
_ R. J. Stouffer, and G. A. Meehl, 2012: An overview of CMIP5 and the experiment design. Bull. Amer. Meteor. Soc., 93, 485498, https://doi.org/10.1175/BAMS-D-11-00094.1.

Vecchi, G. A., and B. J. Soden, 2007a: Increased tropical Atlantic wind shear in model projections of global warming. Geophys. Res. Lett., 34, L08702, https://doi.org/10.1029/ 2006GL028905.

- and — 2007b: Effect of remote sea surface temperature change on tropical cyclone potential intensity. Nature, 450, 1066-1070, https://doi.org/10.1038/nature06423.

Villarini, G., and G. A. Vecchi, 2012: Twenty-first-century projections of North Atlantic tropical storms from CMIP5 models. Nat. Climate Change, 2, 604-607, https://doi.org/ 10.1038/nclimate1530.

Walsh, K., 2004: Tropical cyclones and climate change: Unresolved issues. Climate Res., 27, 77-83, https://doi.org/10.3354/ cr027077.

—, and Coauthors, 2016: Tropical cyclones and climate change. Wiley Interdiscip. Rev.: Climate Change, 7, 65-89, https://doi.org/10.1002/wcc.371.

Wang, B., and J. C. L. Chan, 2002: How strong ENSO events affect tropical storm activity over the western North $\mathrm{Pa}-$ cific. J. Climate, 15, 1643-1658, https://doi.org/10.1175/ 1520-0442(2002)015<1643:HSEEAT > 2.0.CO;2.

, J. Liu, H.-J. Kim, P. J. Webster, S.-Y. Yim, and B. Xiang, 2013: Northern Hemisphere summer monsoon intensified by mega-El Niño/Southern Oscillation and Atlantic multidecadal oscillation. Proc. Natl. Acad. Sci. USA, 110, 5347-5352, https:// doi.org/10.1073/pnas.1219405110.

Wang, C., and L. Wu, 2012: Tropical cyclone intensity change in the western North Pacific: Downscaling from IPCC AR4 experiments. J. Meteor. Soc. Japan, 90, 223-233, https://doi.org/ 10.2151/jmsj.2012-205.

$\longrightarrow$, and - , 2015: Influence of future tropical cyclone track changes on their basin-wide intensity over the western North Pacific: Downscaled CMIP5 projections. Adv. Atmos. Sci., 32, 613-623, https://doi.org/10.1007/s00376-014-4105-4.

- and - 2016: Interannual shift of the tropical uppertropospheric trough and its influence on tropical cyclone formation over the western North Pacific. J. Climate, 29, 4203-4211, https://doi.org/10.1175/JCLI-D-15-0653.1.

Whetton, P., I. Macadam, J. Bathols, and J. O'Grady, 2007: Assessment of the use of current climate patterns to evaluate regional enhanced greenhouse response patterns of climate models. Geophys. Res. Lett., 34, L14701, https://doi.org/10.1029/ 2007GL030025.

Wu, L., and B. Wang, 2004: Assessing impacts of global warming on tropical cyclone tracks. J. Climate, 17, 16861698, https://doi.org/10.1175/1520-0442(2004)017<1686: AIOGWO $>2.0 . \mathrm{CO} ; 2$

_ C. Wang, and B. Wang, 2015: Westward shift of western North Pacific tropical cyclogenesis. Geophys. Res. Lett., 42, 1537-1542, https://doi.org/10.1002/2015GL063450.

Xie, S.-P., and S. G. H. Philander, 1994: A coupled oceanatmosphere model of relevance to the ITCZ in the eastern Pacific. Tellus, 46A, 340-350, https://doi.org/10.3402/ tellusa.v46i4.15484.

C. Deser, G. A. Vecchi, J. Ma, H. Teng, and A. T. Wittenberg, 2010: Global warming pattern formation: Sea surface temperature and rainfall. J. Climate, 23, 966-986, https://doi.org/10.1175/2009JCLI3329.1.

Ying, J., and P. Huang, 2016: The large-scale ocean dynamical effect on uncertainty in the tropical Pacific SST warming pattern 
in CMIP5 models. J. Climate, 29, 8051-8065, https://doi.org/ 10.1175/JCLI-D-16-0318.1.

Yokoi, S., Y. N. Takayabu, and J. C. L. Chan, 2009: Tropical cyclone genesis frequency over the western North Pacific simulated in medium-resolution coupled general circulation models. Climate Dyn., 33, 665-683, https://doi.org/10.1007/s00382-009-0593-9.

Zhan, R., Y. Wang, and X. Lei, 2011: Contributions of ENSO and East Indian Ocean SSTA to the interannual variability of northwest Pacific tropical cyclone frequency. J. Climate, 24, 509-521, https://doi.org/10.1175/2010JCLI3808.1.

Zhang, L., and T. Li, 2014: A simple analytical model for understanding the formation of sea surface temperature patterns under global warming. J. Climate, 27, 8413-8421, https://doi.org/10.1175/JCLI-D-14-00346.1.

Zhang, Q., L. Wu, and Q. Liu, 2009: Tropical cyclone damages in China 1983-2006. Bull. Amer. Meteor. Soc., 90, 489-495, https://doi.org/10.1175/2008BAMS2631.1.
Zhao, H., L. Wu, and W. Zhou, 2011: Interannual changes of tropical cyclone intensity in the western North Pacific. J. Meteor. Soc. Japan, 89, 243-253, https://doi.org/10.2151/jmsj.2011-305.

Zhao, M., and I. M. Held, 2012: TC-permitting GCM simulations of hurricane frequency response to sea surface temperature anomalies projected for the late-twenty-first century. J. Climate, 25, 2995-3009, https://doi.org/10.1175/JCLI-D-11-00313.1.

,-- S.-J. Lin, and G. A. Vecchi, 2009: Simulations of global hurricane climatology, interannual variability, and response to global warming using a 50-km resolution GCM. J. Climate, 22, 6653-6678, https://doi.org/10.1175/2009JCLI3049.1.

_ - and Coauthors, 2013: Robust direct effect of increasing atmospheric $\mathrm{CO}_{2}$ concentration on global tropical cyclone frequency: A multi-model inter-comparison. U.S. CLIVAR Variations, No. 11 (3), U.S. CLIVAR Office, Washington, D.C., 17-23, https://usclivar.org/sites/default/files/USCLIVAR_ VARIATIONS_11_3_Fall2013.pdf. 